\title{
IDENTIDADE NAS COLÔNIAS ALEMÃS DO RS: UMA LEITURA DE VALSA PARA BRUNO STEIN, DE CHARLES KIEFER ${ }^{1}$
}

\author{
Alessandra Paula Rech (UCS) \\ Cristiane da Silva Barcelos (UCS)
}

RESUMO: Este artigo propõe uma leitura de Valsa para Bruno Stein, escrita pelo gaúcho Charles Kiefer, na perspectiva das construções identitárias a partir da diáspora. $O$ estudo aborda conceitos de região e trata do período histórico em que se passa a trama, na década de 1980. Propõe, ainda, algumas reflexões sobre temas emergentes do enredo, como ditadura e racismo, a partir das relações estabelecidas nesse núcleo resultante de imigração alemã no interior do Rio Grande do Sul, retratado por Kiefer. Autores como Stuart Hall, José Clemente Pozenato, Flávio Loureiro Chaves e Boaventura Sousa Santos estão entre as referências.

PALAVRAS-CHAVE: Cultura; Diáspora; Contexto histórico; Identidade; Região.

ABSTRACT: This article proposes a reading of Valsa for Bruno Stein, written by Charles Kiefer, from the perspective of the identity constructions from the diaspora. In order to do so, it approaches regional concepts and deals with the historical period in which the plot is played, in the 1980s. It also proposes some reflections on issues emerging from the plot, such as dictatorship and racism, based on the relations established in this nucleus resulting from German immigration in the interior of Rio Grande do Sul, written by Kiefer. Authors such as Stuart Hall, José Clemente Pozenato, Flávio Loureiro Chaves and Boaventura Sousa Santos are among the references.

KEYWORDS: Culture; Diaspora; Historical Context; Local Identity; Region.

1 Título em inglês: Local identity in the german colonies of Rio Grande do Sul: a reading of Valsa para Bruno Stein, by Charles Kiefer 


\section{APONTAMENTOS INICIAIS}

Este artigo considera as determinantes do espaço e do contexto histórico na obra Valsa para Bruno Stein, de Charles Kiefer, para evidenciar características da construção identitária que se dá a partir da diáspora. Toma como ponto de partida conceitos de região apresentados por autores como José Clemente Pozenato e Flávio Loureiro Chaves e, em uma etapa posterior, se debruça sobre racismo, representações de identidade e alteridade indicativas de características da colônia alemã, recorrendo a autores como Stuart Hall, Boaventura Sousa Santos e Olgário Paulo Vogt. A história se passa na década de 1980, e a edição original do livro é de 1986. Para este artigo, consultamos a oitava edição, publicada no ano de 2006.

Como o título sugere, a trama se desenvolve ao redor do personagem principal, Bruno Stein. O descendente de alemães tem quase 70 anos de idade e trabalha como oleiro. Muito conservador, religioso e autoritário, ele tenta manter a família sob seu controle e de acordo com os hábitos que sempre impôs. Stein se esforça para manter viva a sua pequena olaria, que minguava enquanto ele não admitia a possibilidade de modernizá-la. Sem pensar em parar de trabalhar, mesmo apesar da idade, Stein costumava sempre acompanhar de perto a operação do estabelecimento. 
O autor Charles Kiefer, que é gaúcho, vai além do tradicional chimarrão e utiliza diversas ferramentas para abordar elementos capazes de aproximar o leitor de um cenário no Rio Grande do Sul. Aliás, quando aborda o chimarrão, Kiefer usa, na fala de Bruno, uma explicação tradicional dos gaúchos a quem não tem o hábito da bebida: "[...] a gente sente menos calor depois de um mate quente" (2006, p.114).

A cidade central é Pau-d'Arco, município que não existe no mapa do Rio Grande do Sul, mas Kiefer menciona nomes de alguns destinos reais, como Porto Alegre, Itaqui e Crissiumal, e locais bastante conhecidos, como o Porto de Rio Grande. Outros recursos, ainda, são adotados para familiarizar o enredo com a região em que se passa, como a citação de que um dos funcionários da olaria de Stein, Mário, tinha o costume de ouvir em seu rádio de pilha a Rádio Guaíba (2006, p. 126), que opera no Rio Grande do Sul há mais de 60 anos. A citação do Sport Clube Internacional, time admirado pelo personagem Gabriel (2006, p.199), outro trabalhador da fabriqueta de Stein, é mais um exemplo utilizado.

Apresentamos até aqui considerações iniciais a respeito de alguns pontos que indicam uma regionalidade para a obra e, na sequência, passaremos a explorar algumas questões que 
contribuem para a formação identitária, como o contexto histórico e sinais que apontam para a questão social, bem como trataremos da temática da diáspora.

\section{CONSIDERAÇÕES SOBRE A REGIONALIDADE}

Como fundamento para embasar a análise, iniciamos abordando a questão da região e do espaço na obra. De acordo com Pozenato (2003), tanto o conceito de região quanto a delimitação de uma determinada região são construções, ou seja, na verdade são representações simbólicas (2003, p.151). Para o autor, "só existe como fenômeno aquilo que conseguimos construir na nossa linguagem" (2003, p.151), defendendo que uma região é, então, uma rede de relações. De acordo com Pozenato é preciso compreender a região não como "[...] uma realidade natural, mas uma rede de relações, em última instância, estabelecida por um autor, seja ele um cientista, um governo, uma coletividade, uma instituição ou um líder separatista" (2003, p.152).

O autor faz uma análise da região e da história, recorrendo às ideias de Paul Bois (1960). Diante da discussão a respeito do que constitui uma região, se é o espaço ou a história, Bois defende que é, sem dúvida, a história. Segundo Pozenato, a resposta é que a região é um espaço definido por uma história diferente da de um outro espaço, vizinho e externo (2003, p.152). Por isso, 
ainda conforme Pozenato, para entender uma região deve-se considerar os aspectos sociais, como a história, e não somente aqueles de ordem física ou de paisagem, acrescentando que “a região será melhor entendida se vista como simplesmente um feixe de relações a partir do qual se estabelecem outras relações, tanto de proximidade como de distância" (2003, p.157).

Tomamos essa ideia de "feixe de relações" defendida por Pozenato para pensar a respeito de Valsa para Bruno Stein, buscando compreender o papel da região na obra. Podemos tomar o caso do protagonista, um homem idoso, conservador, que não cogitava qualquer possibilidade de modificar sua opinião e aceitar a modernidade trazida pela televisão, por exemplo: "A televisão te envenenou, despertou no teu coração o desejo e a vaidade do mundo. Verônica, o diabo está rondando a tua vida" (KIEFER, 2006, p.204), diz Stein à neta. Aqui precisamos adiantar o final da obra: Bruno, depois de uma verdadeira revolução interna vivida por meio de suas relações, sobretudo a paixão pela nora, termina sentado em frente à TV, que ele mesmo ligara, algo impensado outrora.

É evidente a mudança de pensamento de Bruno Stein, que concretiza o amor com a nora, bem como a clara quebra de seus paradigmas. Afinal, seria praticamente impossível 
imaginar, no início da obra, que Bruno pudesse sentar-se em frente à televisão, atento às imagens, situação pela qual seu sentimento era de grande asco, enquanto vivia atrelado a questões culturais tradicionais. Embora marcada pelo enquistamento étnico, a colônia alemã à qual pertence está, nesse momento histórico, mais sujeita às relações que a permeiam.

Assim ocorre também com relação à emancipação feminina. Enquanto o protagonista tenta manter o papel de patriarca, elas tomam a frente, seja a neta, Verônica, que decide sair de casa sozinha por ter descoberto estar grávida, seja a nora Valéria, que descobre estar apaixonada pelo sogro. Os direitos da mulher, na década de 1980, ainda engatinhavam no país: o período conhecido como segunda onda feminista foi demarcado entre as décadas de 1960 e 1980, porém, um marco dessa luta só ocorreria em 1985: a criação do Conselho Nacional dos Direitos da Mulher (CNDM), responsável por fomentar ações. Ele foi oficializado por meio da lei federal número 7.353 .

Importante destacar, também, o nome da cidade em que se passa toda a história: Pau-d'Arco. É possível que seja uma referência à obra Corpo de Baile (1965), de Guimarães Rosa. Pau-d'Arco equivale ao Ipê, árvore bastante comum em solo 
gaúcho, mas Kiefer talvez tenha ido além, já que a planta pode estar ligada a uma ideia de crescimento ou de superação, se tomado por base o exemplo usado por Guimarães Rosa. Em A Estória de Lélio e Lina, um dos contos da referida obra, o personagem Lélio encontra um pé de pau-d'arco e o marca para transformá-lo em uma vara quando estiver em ponto de corte, em uma possível metáfora de sua evolução pessoal².

Se considerarmos essa hipótese, Kiefer pode ter escolhido o nome Pau-d'Arco para sinalizar uma possível relação com a trajetória de crescimento interno do protagonista, que vive os anseios de se descobrir apaixonado pela nora e tem os seus costumes conservadores desafiados, principalmente pela neta Verônica, como mencionado. Outro indicativo de que Kiefer possa ter buscado referências na obra de Rosa é que, em Buriti, outro dos contos de Corpo de Baile, Rosa trata sobre o amor entre nora e genro, justamente o que Kiefer abordou na obra. Pode haver, ainda, uma relação com Fausto, de Johann Wolfgang von Goethe. Tal livro foi inspirado em uma lenda alemã na qual médico, mágico e alquimista teria feito um pacto com o diabo.

Conforme análise de Mombach (2012), citações que aparecem no decorrer do livro remetem ao primeiro volume

2 A esse respeito, vide obra da autora Na entrada-das águas, Amor e liberdade em Guimarães Rosa (RECH, 2010, p. 48). 
de Fausto, mais especificamente em relação a um episódio em que Mefistófeles, o diabo, faz uma aposta com Deus: a de que conseguiria convencer Fausto, que era tido como um bom discípulo pela autoridade divina, a cair em tentação (2012, p.140). Necessário observar que Bruno Stein lia Fausto e que se punia pela tentação de ceder aos encantos da nora.

Em outra linha de raciocínio, Santos (2006) aborda a questão do espaço urbano, conceituando-o como aquele que "reúne áreas com os mais diversos conteúdos técnicos e socioeconômicos: [...] podemos, aqui, falar de uma diversidade socioespacial, encaixada em ecologias sociotécnicas recriadas ao longo da história urbana e ampliadas no momento atual" (p.209). Santos propõe que o espaço "seja definido como um conjunto indissociável de sistemas de objetos e de sistemas de ações" (p.12). Para o autor, é preciso analisar não somente o espaço, mas aquilo que o compõe:

Sem dúvida, o espaço é formado de objetos; mas não são os objetos que determinam os objetos. É o espaço que determina os objetos: o espaço visto como um conjunto de objetos organizados segundo uma lógica e utilizados (acionados) segundo uma lógica. Essa lógica da instalação das coisas e da realização das ações se confunde com a lógica da história, à qual o espaço assegura a continuidade (2006, p.24)

Mais adiante, veremos as especificidades dessas relações no contexto da obra. 


\section{RACISMO E ENQUISTAMENTO SOCIAL}

Nos pensamentos do protagonista ou nas falas dos demais personagens, surgem marcas de um racismo velado. O narrador diz que Gabriel, funcionário de Bruno Stein, projetava trabalhar muito, até conseguir comprar uma bicicleta, a qual seria lavada aos sábados e teria a banda dos pneus pintada de branco, além de uma capa para o assento com o tema do Sport Club Internacional, com "a figura do negrinho sorridente". Ou seja, ao se referir ao saci, mascote do clube, sem que houvesse necessidade de caracterizar a cor da pele, evidencia-se o desconforto diante da diferença.

Em outro ponto, observamos mais uma vez o uso de tom pejorativo, quando Mário se refere ao colega mulato como "aquele negro filho da puta": "Vou contar pro velho que aquele negro filho-da-puta tentou me esfaquear" (p.200). Quer dizer, conforme essa postura de Mário, observa-se o sentimento de repulsa e desprezo em relação ao outro, pois a cor de pele não vem ao caso na desavença.

Para Bruno Stein, o fato de seu funcionário Erandi ter gasto o salário do mês em apenas três semanas era "questão de raça", já que o rapaz era mulato. Stein comparava: para ele, o outro empregado, Mário, de pele branca, tinha "controle sobre si mesmo", enquanto Erandi, o mulato, 
era "desregrado, impertinente e arrogante" (2006, p.25). Percebe-se que as relações com o dinheiro são elemento central do pensamento discriminatório. Enquanto um (Erandi) aparece como perdulário e ao mesmo tempo uma ameaça, ao se dizer conhecedor de seus direitos trabalhistas - Stein afirmava que só não o despedia porque ele trabalhava sem carteira assinada e "o mulato fazia questão de lhe lembrar a existência do Ministério do Trabalho" (p.25) -, o outro funcionário (Mário) é valorado pela economia, tida como autocontrole pelo protagonista.

Tais juízos não são exclusividade do personagem principal. Aparecem atrelados à cultura da imigração europeia no Brasil, que se alicerça em um projeto de "branqueamento" da população. Ou seja, quando o governo brasileiro propõe incentivos para a instalação dessas colônias agrícolas, em especial na Região Sul do Brasil, a partir de 1824, assume categoricamente a ideia de substituir gradativamente a mão de obra negra pela de emigrados europeus, provenientes da Itália e da Alemanha.

Esses trabalhadores que venceram condições adversas nos territórios que Ihes foram destinados, chegaram, por outro lado, com o privilégio da terra e de insumos iniciais, o que não ocorreu com os negros libertos. A partir dessa instalação, favorável ainda que desafiadora, estabeleceram-se traços identitários peculiares. 
DaMatta aborda a questão de no passado se libertar um escravo juridicamente, mas sem que ele tivesse condições de libertar-se social e cientificamente, quer dizer, de viver com a dignidade de uma pessoa livre. Aponta que o racismo foi "uma motivação poderosa para investigar a realidade brasileira" (1987, p. 69). O antropólogo faz a seguinte análise:

No século XIX, entretanto, o racismo aparece na sua forma acabada, como um instrumento do imperialismo e como uma justificativa "natural" para a supremacia dos povos da Europa Ocidental sobre o resto do mundo. Foi esse tipo de "racismo" que a elite intelectual brasileira bebeu sofregamente, tomando-o como doutrina explicativa acabada para a realidade que existia no país (1987, p.70).

Sousa Santos (1994) reflete sobre as diferenças culturais como peso maior do que as de raça: "O conceito de imigração substitui o de raça e dissolve a consciência de classe. Tratase, pois, de um racismo de descolonização diferente do racismo de colonização, esse, sim, definitivamente biológico. Em suma, trata-se de um fenômeno de etnicização das minorias" (SOUSA SANTOS, 1994, p.41).

Focando mais atrás, na constituição dessas colônias de emigrados, há um processo conhecido como "enquistamento étnico", como mencionado. Em outras palavras, um fechamento e rigidez de determinados grupos, como a formar 
um cisto no tecido social. No caso das colônias de alemães, tal característica se deve, principalmente, a três fatores que dificultaram a integração desses colonos, segundo Vogt:

a) A concentração de grupos étnicos em áreas geográficas relativamente isoladas; b) a inexistência de políticas públicas estatais voltadas para necessidades mais prementes dos colonos, notadamente no que se refere à educação e à assistência religiosa; c) a ênfase dada, por esses núcleos coloniais, à organização associativa, o que está presente notadamente entre os de descendência germânica (2001, p.49).

Isolados, esses emigrados mantiveram o uso da língua materna, valores religiosos e práticas de trabalho em relação estrita com a mesma etnia, dando origem ao germanismo, à italianidade, à polinidade e à niponicidade, de acordo com o grupo e sua região.

Lembrando que o personagem Bruno Stein é descendente de alemães, Mombach (2012, p.149) destaca que boa parte dos imigrantes vindos da Alemanha para morar no Brasil era de católicos ou protestantes, tendo exercido importante papel na construção da vida religiosa brasileira. Nessa linha, Oberacker Jr. (Apud MOMBACH, 2012) aborda feitos protagonizados por alemães ou descendentes no Brasil, como o fato de freiras alemãs terem inaugurado o Hospital 
Moinhos de Vento (Porto Alegre); o caso de Hermann Dohms, o pastor que foi o fundador da Igreja Evangélica da Confissão Luterana no Brasil; e Dom Cláudio Humes, religioso teutogaúcho, cotado para a sucessão do papa João Paulo II (p.149150), e anos depois, de Bento XVI.

Além do costume de ler a Bíblia, o oleiro Bruno Stein tinha na escrivaninha a obra Fausto, do alemão Goethe. O idioma alemão surge, ainda, em alguns pontos de Valsa..., como em algumas expressões rápidas usadas por Olga, esposa de Bruno Stein, sempre em tom de interjeição. Em uma delas, Olga chama o marido para jantar: "Mann, komm essen" (2006, p.130).

Sobre a imigração alemã no Rio Grande do Sul, Jean Roche destaca que o processo se deu em duas fases: a primeira, compreendida entre os anos de 1824 e 1889, teve a cidade de São Leopoldo marcada como o berço da colonização (1969, p.94), e a segunda foi registrada a partir de 1889 (1969, p.117). A pesquisa de Roche, publicada em 1969, já indicava a inexistência de colonos que falassem apenas o alemão, que havia deixado de ser uma língua exclusiva, embora continuasse sendo a preferida (1969, p.655).

O que se percebe na obra ficcional de Kiefer é que a personagem Olga fala português, mas recorre a diversas 
expressões em alemão, como para dizer o conhecido "Meu Deus": "Mein Gott - exclamou Olga, irrompendo num choro convulso" (2006, p.68). Quer dizer, o emigrado necessita aprender o novo idioma, até mesmo para garantir a convivência social no atual país de moradia, mas mantém as raízes e as expressa, por meio da língua materna, como forma de manter vivo o fio que o liga ao seu local de origem.

A ascendência alemã também fica clara no sobrenome do protagonista, Stein. De acordo com estudo de Carlos H. Hunsche, o sobrenome figura na lista de imigrantes alemães que chegaram na então Colônia São Leopoldo entre 1824 e 1825 (1975, p.108 e 179). Observa-se que, desde 2011, a cidade de São Leopoldo, localizada na região metropolitana da capital gaúcha, Porto Alegre, é oficialmente considerada o berço da colonização alemã no Brasil, definição registrada na lei federal no 12.394, de 4 de março de 2011.

A pequena olaria de Bruno Stein sofria com as novidades surgidas naquela época, ao mesmo tempo em que o oleiro relutava em aceitar modernizar seu modelo de produção. No trecho a seguir, o protagonista discorre sobre as mudanças: "[...] o dinheiro anda escasso, o concreto armado substituiu o tijolo" (KIEFER, 2006, p.175). A obra se passa no final do período de repressão militar, e os reflexos daquele tempo também são citados: 
Naquelas redondezas, todos odiavam Herman Hauser. Depois do golpe militar, à custa de subsídios para culturas inexistentes e empréstimos a juros baixos, fora acrescentando hectares e mais hectares à sua propriedade. Sempre que um colono se encontrava em condição de hipoteca, o gavião rondava a presa até conseguir comprar mais um naco para seu latifúndio. (KIEFER, 2006, p.175).

A mudança tecnológica ameaçando a pequena olaria e a presença perigosa do agiota denunciam o ruir paulatino do mundo do protagonista. Em sua teimosia, Bruno Stein seguia obstinado a manter seu empreendimento nos mesmos moldes de antigamente, sem espaço a ceder para o que fosse novo. O homem, racista e conservador, minguava.

\section{ENTRE HISTÓRIA E LITERATURA}

Os apontamentos anteriores indicam uma aproximação entre história e literatura. Chaves (1991) aponta que "A fronteira, aqui, não se separa; antes, determina o ponto de convergência onde podemos observar a unidade da obra literária" (1991, p. 9). Precisamos, aliás, considerar essa relação para discorrer a respeito da formação identitária presente na obra, que pelo analisado até aqui, deixa claro o peso do período histórico no perfil dos personagens, sobretudo do protagonista. 
Ainda sobre essa ideia, Chaves cita Augusto Meyer:

Só a podemos entender (a literatura) fundindo texto e contexto numa interpretação dialeticamente íntegra, em que tanto o velho ponto de vista que explicava pelos fatores externos, quanto o outro, norteado pela convicção de que a estrutura é virtualmente independente, se combinam como momentos necessários do processo interpretativo (MEYER Apud CHAVES, 1991, p.9).

Pesavento analisa essas ligações quando menciona que o texto literário, ao ser utilizado como recurso para uma construção de conhecimento sobre o mundo, resgatando as sensibilidades de uma época determinada, "poderá dar indícios dos sentimentos, das emoções, das maneiras de falar, dos códigos de conduta partilhados, da gestualidade e das ações sociais de outro tempo $(2000$, p.8).

Chaves recorre a obras de José de Alencar (1829-1877) para abordar a relação entre história e literatura. Conforme Chaves, Alencar definiu três fases da literatura nacional, quais sejam: a primitiva (a respeito de mitos e lendas, entre as quais estava o livro Iracema); a histórica (representando o contato do povo invasor com o espaço brasileiro, citando como exemplos O Guarani e As Minas de Prata), e, ainda, uma etapa até então em desenvolvimento, que trataria de 
valorizar "a cor local" e o resgate do passado, com os exemplos de $O$ tronco de ipê, Til e O Gaúcho. Para Chaves, essas definições caminhavam junto não apenas com um amadurecimento intelectual do autor citado como exemplo, mas também com um projeto "com vistas à aquisição da identidade nacional e sua expressão literária" (CHAVES, 1991, p.16).

Assim, evidencia-se um importante papel do cenário histórico, atual ou já vivido, para a criação literária. Chaves entende que Alencar "provocou a confluência entre a História e a Literatura, justamente no território da ficção", e desta forma, "traçou em linha reta o objetivo final do romance histórico, recém-nascido e já acionado subterraneamente pela força poderosa da ideologia" (1991, p.18). O autor entende que, ao se distanciar do romance que é assumidamente atrelado à história, será possível conhecer uma outra história, “[...] a história que, sem ser rotulada como tal, pode ser inferida do texto de ficção, até inaugurando a medida contra-ideológica da primeira" (CHAVES, 1991, p.19).

Podemos pensar, assim, em Valsa para Bruno Stein como esse modelo sugerido por Chaves, em que o contexto histórico não representa uma trama central, mas que aparece na obra dando subsídios para que o leitor tenha uma compreensão global da obra, ou seja, compreendendo de que forma a história teve - ou não - papel na construção de cada personagem, bem como o peso desse contexto na construção identitária. 
Valsa para Bruno Stein apresenta indícios do período histórico em que se passa: a década de 1980, quando o livro foi publicado originalmente. Trata-se do final da ditadura militar, durante o governo do então presidente João Baptista de Oliveira Figueiredo, cujo mandato ocorreu de 1979 a 1985. Um dos temas emergentes naquele período, a invasão de terras e a reforma agrária, é sinalizado quando é mencionada a distribuição de lotes feita pelo governo na Encruzilhada Natalino, região no entroncamento rodoviário próximo às cidades de Passo Fundo, Sarandi, Carazinho e Ronda Alta, na região Norte do Rio Grande do Sul, durante o governo Figueiredo.

No pano de fundo da obra, a década de 1980, o Brasil vencia o mais forte período de repressão da sua história, a ditadura militar, iniciada em 1964 e findada mais de 20 anos depois, em 1985. Em estudo sobre a ditadura, Ronaldo Costa Couto dá uma ideia do que se passava na metade da década de 1980, quando, em 1985, o país empossava o primeiro presidente - mesmo que de forma indireta - após os anos de repressão:

A travessia está concluída. A transição se completou. Não foi apenas o governo que mudou, mas o regime político. O Brasil já é, de fato e de direito, uma democracia política. A maior prioridade agora é 
consolidar a transição. Remover a legislação autoritária remanescente, institucionalizar o estado de direito, escrever nova carta política por intermédio de assembleia nacional constituinte livre e soberana. É o que acontece. A democracia se consolida rapidamente, livre da tutela militar, estável e talvez irreversível (2003, p.443)

Outro dado importante mencionado em Valsa... é a existência de minifúndios alemães no Rio Grande do Sul. Na história, Kiefer cita a Pastoral da Terra (2006, p.214), criada pela Igreja Católica em junho de 1975 para desenvolver o trabalho no campo. Essa foi uma forma encontrada para quebrar o monopólio de poder por parte dos maiores proprietários de cada região (KUCINSKI, 2001, p.112). Era nessa época, mas um pouco antes de grandes greves operárias que marcaram a segunda metade da ditadura, que se iniciava uma luta, de certa forma silenciosa, de parte de posseiros de terra que não dispunham de títulos legais de posse de seus territórios e de grandes fazendeiros ou grupos econômicos, que tentavam se apossar desses locais valendose de documentos nem sempre legítimos (2001, p.113). Trata-se de mais pontos históricos importantes e que não deixam de ser abordados no livro.

Kiefer traz esses temas à tona quando menciona que colonos sem-terra haviam acampado dentro do limite 
pertencente a Bruno Stein (2006, p.212). É válido destacar que não estamos aqui propondo qualquer debate entre verdade ou ficção na obra literária em análise, mas apresentando elementos para compreender a relevância do contexto histórico para a trama. Isso é explicado por Terry Eagleton: "a distinção entre 'fato' e 'ficção', portanto, não parece nos ser muito útil, e uma das razões para isso é que a própria distinção é muitas vezes questionável" (2006, p. 2). Eagleton remonta a um exemplo britânico para fundamentar a linha de raciocínio:

No inglês de fins do século $X V I$ e princípios do século XVII, a palavra "novel" foi usada, ao que parece, tanto para os acontecimentos reais quanto para os fictícios, sendo que até mesmo as notícias de jornal dificilmente poderiam ser consideradas fatuais. Os romances e as notícias não eram claramente fatuais, nem claramente fictícios, a distinção que fazemos entre estas categorias simplesmente não era aplicada [...]. Além disso, se a "literatura" inclui muito da escrita "fatual", também exclui uma boa margem de ficção $(2006$, p.2)

Assim, se Valsa para Bruno Stein tem bases em determinado contexto histórico, essa informação terá relevância equivalente à bagagem do leitor em questão, por meio de seus conhecimentos prévios, sua curiosidade e sua formação. Recorremos ao seguinte argumento de Eagleton 
para explicar: "A definição de literatura fica dependendo da maneira pela qual alguém resolve ler, e não da natureza daquilo que é lido" (2006, p.12). O autor destaca que, de acordo com cada leitor, "todas as obras literárias "são 'reescritas', mesmo que inconscientemente, pelas sociedades que as leem" (2006, p.19):

O fato de sempre interpretarmos as obras literárias, até certo ponto, à luz de nossos próprios interesses - e o fato de, na verdade, sermos incapazes de, num certo sentido, interpretá-las de outra maneira - poderia ser uma das razões pelas quais certas obras literárias parecem conservar seu valor através dos séculos. Pode acontecer, é claro, que ainda conservemos muitas das preocupações inerentes à da [sic] própria obra, mas pode ocorrer também que não estejamos valorizando exatamente a "mesma obra". O "nosso" Homero não é igual ao Homero da Idade Média, nem o "nosso" Shakespeare é igual ao dos contemporâneos desse autor (2006, p.18)

O que Eagleton pretende mostrar é que a literatura é definível pela linguagem que emprega, e não pelo fato de ela ser ficcional ou não. Assim, nota-se que o contexto histórico não se mostra como um aspecto crucial, mas complementar, que nada significaria não fosse seu perfeito encaixe no desenrolar da história. 


\section{CONSTRUÇÕES IDENTITÁRIAS A PARTIR DA IDEIA DE DIÁSPORA}

Passamos a refletir sobre a diáspora na construção identitária, tomando como base, em Valsa para Bruno Stein, a origem alemã do protagonista e seus familiares. A diáspora, entendida como o fenômeno de dispersão ou espalhamento de um povo, é um conceito amplamente conhecido a partir da história do povo judeu. No entanto, com o passar dos tempos e a ocorrência de tantos outros processos de migração, mudaram os tipos de arranjos sociais entendidos como diásporas.

Se esses moradores deixam seus países de origem forçados ou por desejo próprio, acabam buscando ferramentas e conservando hábitos e costumes para, de alguma forma, conseguirem manter o elo com a terra natal. Exemplos disso são o uso da língua, mesmo que em expressões isoladas dentro do contexto de uma conversação, seja por meio do preparo de alimentos típicos, realização de danças e outras atividades culturais, bem como, naturalmente, a forma de pensar e até de agir. Em Valsa..., como já mencionado anteriormente, observamos as falas de Olga, esposa de Bruno Stein, bem como costumes dele próprio, que tinha às mãos a obra Fausto, do alemão Goethe, por exemplo. 
Em artigo escrito com base em uma palestra realizada em 1998, Hall, partindo da noção de identidade cultural dos migrantes caribenhos, reflete sobre a busca de identificação com a cultura de origem do sujeito: "aquilo que poderíamos denominar 'identificação associativa' com as culturas de origem permanece forte, mesmo na segunda ou terceira geração, embora os locais de origem não sejam mais a única fonte de identificação" (2003, p. 26). E continua: "A força do elo umbilical está refletida também nos números crescentes de caribenhos aposentados que retornam" (2003, p. 26). Chama a atenção o termo usado por Hall para falar dessa ligação, "umbilical", denotando a ideia de uma relação forte, de extrema conexão, e é esse elo que o autor chama de tradição:

Possuir uma identidade cultural nesse sentido é estar primordialmente em contato com um núcleo imutável e atemporal, ligando ao passado o futuro e o presente numa linha ininterrupta. Esse cordão umbilical é o que chamamos de "tradição", cujo teste é o de sua fidelidade às origens, sua presença consciente diante de si mesma, sua "autenticidade". E, claro, um mito com todo o potencial real dos nossos mitos dominantes de moldar nossos imaginários, influenciar nossas ações, conferir significado às nossas vidas e dar sentido à nossa história. (2003, p.29) 
Para Hall, existem reflexões surgidas a partir da diáspora, como a identidade, a diferença e o pertencimento após esse movimento de mudança. Destaca que a família, como rede e local da memória, constitui o "canal crucial entre os dois lugares" (p.26). Trata-se do papel fundamental da rede familiar na manutenção dos laços e, também, na construção de novas conexões identitárias, desta vez com o novo local de vivência do sujeito.

Bruno Stein, personagem central da obra literária que analisamos neste artigo, é um homem devoto da religião protestante, que comparece ao culto todos os domingos e que sempre reza antes de dormir. Segundo Mombach (2012), os imigrantes que chegaram ao Brasil eram em geral protestantes ou católicos, e tiveram importante papel na vida religiosa brasileira:

Kiefer faz uso dessa religiosidade alemã na construção da identidade de Bruno Stein; é através dos olhos da religião que este julgava a vida à sua volta: as pessoas, a televisão, o comportamento de cada um, o casamento, etc. O protagonista sempre se amparava na fé, crente de que essa lhe conferia a iluminação necessária para prosseguir, acreditando que as contradições do mundo e dos homens existiam para "testar os crentes, para prová-los até o limite de suas forças" (2012, p.150) 
Em relação a esse assunto, Vogt destaca a religiosidade como um elemento para ajudar os alemães a conservar um pouco do que eram antes de deixar a Europa para cruzar o oceano e encontrar um lugar novo para viver:

A devoção e o zelo religioso dos teutos e de seus descendentes colaboraram para a preservação da germanidade. Os luteranos, que até a Proclamação da República viveram em uma pátria em que a religião oficial era a católica, professavam todos os rituais de seu credo na língua germânica, idioma em que também eram editados a bíblia e os hinários (2001, p.52)

Essa marca da religiosidade como ferramenta para manter viva uma cultura, aliás, também se mostra em relação a outras etnias, como a italiana. A imigração de italianos foi muito forte especialmente em direção ao sul do Brasil, a partir de 1875, e sinalizada pela construção de vilas onde havia sempre uma capela. Quer dizer, por meio de um templo onde pudessem manifestar e conservar sua fé, denota a participação da religião como elemento para manter o elo com o que ficou e, consequentemente, participar da construção da identidade do, a partir de então, morador de solo brasileiro.

Falamos em identidades adaptáveis à realidade em que estão inseridas, aos mesmo tempo em que absorvem o que 
o ambiente ao redor do sujeito proporciona. Sousa Santos (1993) aborda identidades culturais como resultados de processos de identificação, ou seja, que em nada são rígidas ou imutáveis. Qualquer identidade está sujeita a processos de transformação, porque, para o autor, identidades são "identificações em curso" (1993, p.31).

O que se pode pensar é na formação de uma identidade que não despreza as raízes culturais carregadas desde o local de origem, e que é acrescida pelas vivências e pela construção de relações apreendidas na nova terra, em uma espécie de cruzamento de informações de vida. Em relação a isso, percebe-se que, para Hall, em casos de diáspora, as identidades se tornam múltiplas (2003, p.27). Tal pensamento é coerente com a trajetória do personagem que, embora resistente, se modifica ao longo da trama.

\section{CONSIDERAÇÕES FINAIS}

Romance com ingredientes históricos, Valsa para Bruno Stein aposta em diversos elementos capazes de diminuir a linha que separa o leitor de um mergulho profundo na trama proposta por Charles Kiefer. Ao apresentar recursos que indicam uma regionalidade - sem excessos, uma vez que não se trata de uma obra regionalista, por não exaltar de forma laudatória a região em que se passa a obra -, Kiefer leva 
o leitor ao interior do Rio Grande do Sul, na fictícia cidade de Pau-d'Arco, e mais: ajuda a projetar uma identidade para os personagens, sobretudo o protagonista, que dá nome à obra.

Retratando a década de 1980 e o começo da libertação do país, sofrida por longos 21 anos de ditadura militar, o livro mostra como o cenário de repressão, machismo e preconceito refletem na formação dos personagens. $O$ sentimento de pertencimento à terra natal também é percebido, por meio das manifestações de personagens.

Se a religiosidade significa um elemento de ligação do povo que viveu a diáspora, como salienta Vogt, isso é demonstrado pelo livro, bem como o papel das vivências na construção da identidade. Talvez uma prova de adesão entre obra e teorias seja a metamorfose vivida pelo protagonista, que se apaixona e se envolve com a nora e, ao fim da obra, acaba seduzido pela televisão, aquela que ele tanto combateu. Exatamente como pregou Sousa Santos, dizendo que as identidades não são estanques, mas "identidades em curso".

\section{REFERÊNCIAS}

A LUTA do Acampamento Encruzilhada Natalino (2001). "Movimento dos Trabalhadores Rurais Sem Terra". In http://www.mst.org.br/2014/06/18/ a-luta-do-acampamento-encruzilhada-natalino.html. Acesso em 20.Jun. 2018.

CHAVES, Flávio Loureiro (1991). História e literatura. Porto Alegre: Editora da Universidade Federal do Rio Grande Sul. 
COUTO, Ronaldo Costa (2003). História indiscreta da ditadura e da abertura. Brasil: 1964-1985. Rio de Janeiro: Record.

DAMATTA, Roberto (1987). Relativizando: Uma introdução à antropologia social. Rio de Janeiro: Rocco.

EAGLETON, Terry (2006). Teoria da literatura: uma introdução. São Paulo: M. Fontes.

HALL, Stuart (2003). Da diáspora - identidades e mediações culturais. Belo Horizonte: UFMG.

HUNSCHE, Carlos H. (1975). O biênio 1824/25 da imigração e colonização alemã no Rio Grande do Sul (Província de São Pedro). Porto Alegre: A Nação.

KIEFER, Charles (2006). Valsa para Bruno Stein. Rio de Janeiro: Record. KUCINSKI, Bernardo (2001). O fim da ditadura militar. São Paulo: Contexto. MOMBACH, Clarissa (2012). Um fausto brasileiro? Uma análise intertextual de Valsa para Bruno Stein. Literatura em Debate. Porto Alegre, 6(11), 139153, dez.

PESAVENTO, Sandra Jatahy (Org) (2000). Leituras Cruzadas: diálogos da história com a literatura. Porto Alegre: Editora da Universidade Federal do Rio Grande do Sul.

POZENATO, José Clemente (2003). Processos culturais - reflexões sobre a dinâmica cultural. Caxias do Sul: Educs.

RECH, Alessandra (2010). Na entrada-das-águas: amor e liberdade em Guimarães Rosa. Caxias do Sul: Educs.

ROCHE, Jean (1969). A colonização alemã e o Rio Grande do Sul. Porto Alegre: Globo,1v.

SANTOS, Milton (2006). A natureza do espaço - Técnica e tempo. Razão e emoção. São Paulo: Editora da Universidade de São Paulo.

SOUSA SANTOS, Boaventura de. (1993). "Modernidade, identidade e a cultura de fronteira". Tempo Social. 5, 31-52, São Paulo: USP. In http://www. boaventuradesousasantos.pt/media/Modernidade\%20ldentidade\%20 Fronteira_TempoSocial1994.pdf. Acesso em 30.Mar.2019. 
(1994) Pela mão de Alice - O social e o político na pósmodernidade. Porto: Edições Afrontamento.

VOGT, Olgário Paulo (2001). "Imperialismo, a face oculta do germanismo". Revista Ágora. Santa Cruz, 7(2) 2, 49-92, jul-dez.

Alessandra Rech é Doutora em Letras - Literatura Brasileira pela UFRGS. Desenvolve estágio pós-doutoral no Programa Avançado de Cultura Contemporânea (PACC) da UFRJ. É autora, entre outros, do ensaio $\mathrm{Na}$ entrada-das-águas, amor e liberdade em Guimarães Rosa (Educs, 2010) e de Mirabilia, crônicas (Belas Letras, 2014), vencedor do Prêmio Vivita Cartier de Literatura. Professora colaboradora do Mestrado em Letras e Cultura da UCS, pesquisa o programa Residência Criativa desenvolvido na Casa do Sol, de Hilda Hilst, com financiamento do CNPq. E-mail: aprech1@ ucs.br.

Cristiane Barcelos é Mestre em Letras, Cultura e Regionalidade pela UCS, tendo defendido a dissertação intitulada "Vozes do Recriar Textos: a produção literária dos internos do CASE, de Caxias do Sul, como representação do contexto socioeducativo em regime de reclusão", com financiamento da CAPES. É jornalista, com experiência de mais de 10 anos em reportagem e edição. E-mail: cristiane.barcelos2@gmail.com. 